\title{
O CONCEITO DE “GAMEPLAY EXPERIENCE” APLICADO À LOCALIZAÇÃO DE GAMES
}

\author{
कीक्रिक \\ RiCARDO ViniCIUS FERRAZ DE SOUZA ${ }^{1}$
}

Resumo: O principal objetivo de um game é proporcionar diversão. Para isso, é fundamental ter em mente o conceito de "gameplay experience”, em que se procura oferecer a(o) jogador(a) uma experiência interativa que lhe seja prazerosa e que lhe permita apreciar uma boa narrativa, derrotar um oponente, cumprir uma missão, entre outros, sem ter sua atenção desviada para outros fatores que possam vir a comprometer sua diversão. O presente trabalho visa analisar o conceito de "gameplay experience” sob a ótica da localização de games, buscando entender em que medida a tradução de um game pode contribuir para uma experiência de jogo mais/menos agradável. Em primeiro lugar, serão apresentadas algumas definições dos termos "gameplay" (comumente traduzido como “jogabilidade”) e "gameplay experience" (ou "experiência de jogo"), de modo a melhor compreender os aspectos que os envolvem. Em seguida, examinaremos o conceito de "gameplay experience" dentro do universo da localização de games. Por fim, serão apresentados alguns exemplos retirados das versões brasileiras de alguns games, a fim de visualizarmos na prática a importância da tradução para uma experiência de jogo mais divertida.

Palavras-chave: Localização. Videogames. Gameplay. Gameplay experience.

\begin{abstract}
The main goal of a video game is to provide fun. In this regard, it is essential to bear in mind the concept of "gameplay experience", which has to do with providing the players with a pleasant interactive experience that allows them to enjoy a good narrative, defeat an opponent, complete a mission, etc, without having their attention diverted to other factors which could eventually compromise the fun. This paper aims at analyzing the concept of "gameplay experience” under the perspective of video game localization, trying to understand to what extent the translation of a video game may contribute to a more/less pleasant gameplay experience. First, some definitions of the terms "gameplay" (commonly translated as "jogabilida$d e$ ") and "gameplay experience" (or "experiência de jogo") are discussed, so as to increase the understanding of their various aspects. Next, the concept of "gameplay experience" within the world of video game localization is examined. Finally, some examples taken from the Brazilian versions of some video games are presented in order to see in practice the importance of translation for a more fun gameplay experience.
\end{abstract}

Keywords: Localization. Video games. Gameplay. Gameplay experience.

\footnotetext{
${ }^{1}$ Ricardo Vinicius Ferraz de Souza é mestrando do Programa de Pós Graduação em Estudos da Tradução pela Universidade de São Paulo (USP). É bolsista pela Fundação de Amparo à Pesquisa do Estado de São Paulo (FAPESP). Graduou-se em Letras (Português/Espanhol) pela Faculdade de Filosofia, Letras e Ciências Humanas da Universidade de São Paulo (FFLCH/USP). É autor dos seguintes artigos: Video Game Localization: the case of Brazil (Tradterm, vol. 19, nov. 2012) e Venuti e os Videogames: o conceito de domesticação/estrangeirização aplicado à localização de games (In-Traduções, v.5, n. esp. Games e tradução, out. 2013). Suas áreas de interesses de pesquisa incluem: Tradução Intersemiótica, Games, e Localização de Games.
} 
S empre que lemos, vemos ou escutamos a análise de um determinado game - seja em um site ou vídeo na internet, em alguma revista especializada ou até mesmo em uma conversa entre amigos -, observamos que certos elementos são levados em consideração no veredito do analista. Muitas vezes, o jogador analisa elementos como os gráficos, o nível de dificuldade, os modos single-player e multiplayer, entre outros, para decidir se deve ou não investir seu tempo para jogar tal game. Dentre os elementos comumente observados nessas análises, um que aparece com bastante frequência, e que é tido como essencial para o sucesso ou não de um game, é o que se conhece por gameplay (ou jogabilidade). Ao examinarmos a análise do site UOL Jogos para o game The Legend of Zelda: A Link Between Worlds (Nintendo, 2013), por exemplo, lemos que "[o] game de 3DS busca manter a essência da jogabilidade clássica de aventura e exploração de 'Zelda' [...]”' (Lippe, 2013 [grifo nosso]; já o site norte-americano IGN cita como um dos pontos positivos do game XCOM: Enemy Within (2K Games/ Firaxis, 2013) a sua "ótima jogabilidade tática"2 (Stapleton, 2013 [tradução e grifo nossos] ${ }^{3}$. Como se vê, o gameplay ${ }^{4}$ parece ser um elemento importante para o sucesso de um game. Porém, o que vem a ser exatamente gameplay? Quais elementos abarca? Enfim, o que se faz necessário para que o gameplay transmita uma experiência agradável ao jogador ao longo de um game?

\section{O conceito de "gameplay"}

Em busca de respostas paras as questões acima, grandes esforços têm sido empreendidos com vistas a encontrar uma definição para o termo gameplay. Ao longo do tempo, uma ampla variedade de definições foi proposta a fim de melhor compreender os aspectos que envolvem o conceito. No entanto, essa tarefa têm se mostrado um tanto complexa, na medida em que, a despeito das inúmeras definições apresentadas, ainda não se chegou a um "acordo" acerca do "real e exato" significado de gameplay. Nesse sentido, pode-se dizer que o termo é um tanto controverso, fazendo com que suas definições acabem apresentando variações conforme a maneira como cada autor enxerga o conceito. Com base nisso, serão apresentadas aqui algumas definições propostas por alguns autores para o termo gameplay. $\mathrm{O}$ objetivo principal dessa apresentação é, por meio da análise de diferentes visões e opiniões procurar mapear os principais elementos referentes ao gameplay, de modo a tentar estabelecer uma visão um pouco mais abrangente do conceito.

Primeiramente, Andrew Rolling e Dave Morris, no capítulo sobre gameplay de seu livro Game Architecture and Design: A New Edition (2004), citam os seguintes aspectos do conceito:

\footnotetext{
${ }^{2}$ Great tactical gameplay.

${ }^{3}$ Todas as traduções de excertos de obras estrangeiras neste artigo foram realizadas pelo autor.

${ }^{4}$ Até aqui, os termos "gameplay" e "jogabilidade" foram utilizados para apresentar o termo original em inglês e a sua respectiva tradução ao português. A partir de agora, o termo "gameplay” será o termo utilizado ao longo do texto, até mesmo para manter a uniformidade entre os vocábulos "gameplay” e "gameplay experience”, algo que não ocorreria com as respectivas traduções ao português, “jogabilidade” e "experiência de jogo”.
} 
Também é importante notar que o game deve ser uma série de escolhas interessantes. Cada decisão afetará a seguinte [...] Portanto, um game permite estratégia. De fato, um game bem concebido não pode ser vencido sem estratégia. E a estratégia se manifesta como uma série de escolhas interessantes [...] Tudo isso exige que o game demonstre complexidade. Isso não significa, contudo, que as regras, por si só, devam ser complexas. ${ }^{5}$ (Rollings e Morris, 2004, p.62 [grifos nossos])

Como se vê, os dois autores destacam quatro elementos: escolhas interessantes, decisão, estratégia e regras. Para eles, para que um game seja atraente, fazse necessário oferecer ao jogador a possibilidade da escolha. Mas não se trata, aqui, de uma escolha pura e simples: deve ser interessante, incentivar o jogador a seguir em frente e impulsioná-lo a buscar alternativas para superar os obstáculos que se lhe apresentam. Nesse sentido, o fato de lidar com escolhas interessantes faz com que cada decisão, naturalmente, afete as demais decisões; isto é, ela influenciará os próximos passos que o jogador deverá seguir ao longo do game. Como consequência disso, ao tomar suas decisões, o jogador deverá ser bastante criterioso acerca do que fazer. A partir daí, ele passa a desenvolver estratégias a fim de tomar a decisão mais apropriada que lhe permita completar o seu objetivo, e, por conseguinte, seguir em frente no game. Contudo, todo esse processo não se dá de maneira aleatória: é preciso que tudo isso seja feito dentro de regras. Embora, segundo os autores, as regras não devam ser complexas, o simples fato de que as escolhas, as decisões e as estratégias a serem seguidas estejam condicionadas a certos parâmetros acabam por impor ao jogador um certo grau de complexidade, o que acaba por tornar o gameplay mais desafiador e, como resultado, mais atraente ao jogador.

Já nas primeiras páginas de seu livro, Fundamentals of Game Design (2010), Ernst Adams apresenta o conceito de gameplay da seguinte maneira:

O gameplay consiste de:

- Desafios que um jogador deve enfrentar para chegar ao objetivo do game.

- Ações que o jogador está autorizado a tomar para enfrentar esses desafios." (Adams, 2010, p. 11 [grifos nossos])

No caso de Adams, o foco está em dois elementos: desafios e ações. Segundo ele, "um desafio é qualquer tarefa estabelecida para o jogador que não seja trivial de se realizar"” (Adams, 2010, p. 10). Para Adams, os desafios se apresentam de maneira "hierarquizada": um desafio maior é proposto ao jogador para que o objetivo do game seja concluído. Mas, para atingir tal objetivo, o jogador deverá enfrentar uma série de desafios menores, igualmente importantes e que ajudarão a conduzir o jogador rumo à conclusão do objetivo principal (Adams, 2010, p. 10). Com relação às ações, o autor cita um aspecto já mencionado por Rollings e Morris: regras. Segundo Adams, são as regras que permeiam as ações a serem tomadas

\footnotetext{
5 "Also it's important to note that the game must be a series of interesting choices. Each decision affects the next. [...] Hence, a game allows strategy. Indeed, a well-designed game cannot be won without strategy. And strategy manifests itself as a series of interesting choices [...] All this requires the game to display complexity. This doesn't mean, however, that the rules themselves must be complex".

6 “Gameplay consists of:

- The challenges that a player must face to arrive at the object of the game.

- The actions that the player is permitted to take to address those challenges."

7 "A challenge is any task set for the player that is nontrivial to accomplish."
} 
pelos jogadores. Para ele, "as regras definem não apenas as ações que são permitidas, mas também quais delas são proibidas e quais são exigidas e sob quais circunstâncias" ${ }^{\prime 8}$ (Adams, 2010, p. 11). Nesse sentido, pode-se dizer que as regras condicionam o jogador no que diz respeito às suas decisões frente ao desafio. A partir disso, ele pensará nas ações (ou estratégias) que lhe permitirão superar os desafios para concluir o seu objetivo.

Por fim, em Game Development Essentials (2012), Jeannie Novak apresenta a seguinte definição de gameplay:

O gameplay pode ser definido como escolhas, desafios ou consequências que os
jogadores enfrentam ao navegar em um ambiente virtual. [...] Para cada desafio
(ou ponto de virada), pense nas muitas estratégias que podem ser utilizadas pelo
jogador (ou personagem em uma história) para superá-lo. Pode-se argumentar
que o gameplay é o que realmente torna um game envolvente. ${ }^{9}$ (Novak, 2012, p.
184 [grifos nossos]).

No caso de Novak, o gameplay é constituído por escolhas, desafios, consequências, estratégias, além de ser o que faz do game algo envolvente. Nesse cenário, cada desafio proposto proporciona ao jogador a oportunidade de efetuar escolhas, ou seja, planejar estratégias que o levem a ultrapassar o obstáculo apresentado pelo desafio. Assim como em Rollings e Morris, essas escolhas acarretarão em consequências que influirão nos próximos movimentos do jogador. E é justamente esse emaranhado de possibilidades que fará do game algo envolvente. Além disso, Novak também reconhece a importância das regras para o gameplay e - a exemplo de Rollings e Morris, e de Adams - o quanto elas influenciam nas ações empreendidas pelo jogador. Ela cita o fato de que: "todos os games contêm regras [...] As regras de um game definem as ações ou movimentos que os jogadores podem fazer em um game (e também aqueles que eles não podem fazer)"10 (Novak, 2012, p. 184 [grifos nossos]).

Ao examinar as três definições, é possível observar alguma consonância na maneira como enxergam o conceito de gameplay. Em alguns casos, nota-se a utilização de termos em comum, tais como escolha, estratégia, desafio, regra; já em outras situações, empregam-se termos/descrições diferentes para abordar coisas similares, como no caso de que cada decisão adotada pelo jogador irá interferir na decisão subsequente (Rollings e Morris, 2010, p. 62), que se assemelha ao fato de que as escolhas realizadas pelos jogadores gerarão consequências em suas próximas escolhas (Novak, 2012, p. 184). Pode-se perceber também, na visão dos autores, certo padrão na maneira como cada um desses elementos interage entre si. Com base nisso, é possível pensar o conceito de gameplay da seguinte forma:

\footnotetext{
8 "The rules define not only what actions are allowed but also which ones are prohibited and which ones are required and under what circumstances."

9 "Gameplay can be defined as choices, challenges, or consequences that players face while navigating in a virtual environment. [...] For each challenge (or plot point), consider the many strategies that can be used by a player (or character in a story) to overcome it. It can be argued that the gameplay is what truly makes a game compelling."

10 "All games contain rules [...] The rules of a game define the actions or moves that the players may make in the game (and also those that they cannot make)."
} 
A. Cada game possui um objetivo (ou uma série de objetivos).

B. Para se atingir tal objetivo, o jogador deverá enfrentar uma série de desafios.

C. De modo a superar esses desafios, o jogador precisará elaborar estratégias.

D. A partir dessa estratégia, o jogador efetuará suas escolhas, decisões e ações.

E. Contudo, todas essas estratégias, escolhas, decisões e ações estão condicionadas e deverão ser realizadas à luz das regras do game.

F. Cada uma dessas escolhas, ações e decisões trarão consigo as suas consequências e influenciarão os próximos atos a serem seguidos pelo jogador.

G. E é exatamente a interação bem-sucedida entre cada um desses elementos que tornará o game interessante e envolvente.

\section{O conceito de "gameplay experience"}

Uma vez examinado o conceito de gameplay, uma nova questão naturalmente se nos apresenta: o conceito de gameplay experience. O que vem a ser gameplay experience? Como os elementos do gameplay se relacionam com a gameplay experience? A exemplo do que fizemos com relação ao conceito de gameplay, serão examinadas algumas definições do conceito de gameplay experience, com o mesmo intuito de tentar apresentar um panorama acerca do conceito, para, assim, tentar depreender suas principais características. Em Fun Experience with Digital Games: A Model Proposition (2007), Amyris Fernandez, ao discorrer sobre modelos de avaliação da experiência e da diversão em games (além de propor o seu próprio), afirma que:

[...] o objetivo do usuário é divertir-se, uma experiência emocional e cognitiva que resulta da interação com o ambiente do game e com outros jogadores. ${ }^{11}$ (Fernandez, 2007, p.1 [grifos nossos])

Por sua vez, logo no resumo introdutório de seu artigo intitulado Methods for Evaluating Gameplay Experience in a Serious Gaming Context (2010), Lennart Nacke, Anders Drachen e Stefan Göbel seguem uma linha semelhante:

A Gameplay experience (GX) é criada durante o processo de interação jogadorgame, em que essa interação tem por objetivo proporcionar uma experiência motivadora, divertida para o jogador. ${ }^{12}$ (Nacke, Drachen e Göbel, 2010, p.1 [grifos nossos])

Se observarmos com atenção, é possível perceber que o item G apresentado na seção 2 (sobre gameplay) já nos dava um pequeno vislumbre do conceito de gameplay experience, algo que os trechos acima acabam por confirmar, vindo a

\footnotetext{
${ }^{11}[\ldots]$ the user`s goal is to have fun, an emotional and cognitive experience resulting from the interaction with the game environment and with other players.

${ }^{12}$ Gameplay experience (GX) is created during the process of player-game interaction, where this interaction has the goal to provide a motivating, fun experience for the player.
} 
acrescentar a ele a relação jogador/game. Como no caso de gameplay, existe uma recorrência no uso de certos termos aqui, em especial os que se referem à interação jogador/game e à diversão. Em ambas as obras examinadas, a gameplay experience se origina na interação entre o jogador e o game. Expandindo essa noção, percebemos que a interação se dá por meio da maneira como o jogador se relaciona com o game e no modo como se comporta frente ao "ambiente do game" (Fernandez, 2007, p.1), ou seja, a forma como o jogador reage frente ao gameplay e seus objetivos, regras, desafios, estratégias, escolhas, decisões, ações e consequências, com os quais se depara ao jogar o game.

Além disso, como bem observa Fernandez, essa interação acaba por gerar uma experiência ao mesmo tempo cognitiva e emocional. Por exemplo, a fim de superar um desafio e cumprir um determinado objetivo, o jogador deverá utilizar toda a sua capacidade cognitiva, isto é, seu raciocínio, memória, atenção, etc, de modo a elaborar a melhor estratégia, a tomar a melhor decisão, enfim, a encontrar a melhor maneira de solucionar um problema - baseado na experiência e no conhecimento adquiridos ao longo de sua interação com o game. Como resultado, esse processo ativa também o seu lado emocional, visto que o jogador pode vir a demonstrar, por exemplo, medo ou ansiedade por enfrentar um inimigo poderoso; raiva ou frustração por não conseguir superar um desafio; ou ainda alegria por ter sido capaz de atingir um objetivo. Nesse sentido, essa interação jogador/game permite ao jogador utilizar o seu lado racional, ao mesmo tempo em que evoca seu lado sentimental. E é exatamente o êxito nessa interação o responsável por proporcionar ao jogador uma gameplay experience agradável, fazendo com que a experiência de jogar o game seja divertida. Diante disso, pode-se inferir que o conceito de gameplay experience é constituído:

A. Por uma interação entre o jogador e o game.

B. Essa interação se dá pelo modo como o jogador se comporta com relação aos elementos do gameplay (objetivos, desafios, estratégias, escolhas, etc.)

C. A interação com esses elementos aciona o lado cognitivo do jogador, fazendo com que use suas habilidades e conhecimentos para melhor lidar com eles.

D. Por sua vez, essa interação também desperta o lado emocional do jogador, que pode vir a demonstrar as mais variadas emoções de acordo com o desenrolar de suas ações no decorrer dessa interação.

E. Todo esse processo interativo terá um papel fundamental em cumprir o objetivo de cada game: proporcionar diversão.

\section{“Gameplay Experience” e a Localização de Games}

Diante do que foi visto até aqui, como o conceito de gameplay experience se situa no universo da localização de games? Até que ponto a versão de um game em outro idioma pode interferir na gameplay experience? Ao contrário do que se poderia pensar, a tradução desempenha um papel fundamental para a diversão, uma vez que busca reproduzir na versão localizada a mesma gameplay experience desfrutada pelo jogador da versão original. Nesse sentido, em Game Localisation: Un- 
leashing Imagination with 'Restricted' Translation (2006), Carmen Mangiron e Minako O’Hagan afirmam que:

\begin{abstract}
A principal prioridade da localização de games é preservar a gameplay experience para os jogadores-alvo, mantendo a 'aparência e a sensação' do original. O mandato do localizador é o de produzir uma versão que permitirá aos jogadores experimentar o game como se fora originalmente desenvolvido em seu próprio idioma e proporcionar diversão semelhante àquela sentida pelos jogadores da versão original. ${ }^{13}$ (Mangiron e O’Hagan, 2006, p. 14-15)
\end{abstract}

Fica claro por esse trecho que a localização tem por objetivo proporcionar, da maneira mais próxima possível, a mesma experiência oferecida pela versão original, fazendo com que o jogador da versão localizada tenha os mesmos subsídios proporcionados ao jogador da versão original para usufruir do game. Mas, o que fazer para que esse tipo de abordagem tradutória seja adotado a fim de que se atinja um nível de gameplay experience semelhante ao do original?

De fato, o maior foco da localização de games está no gameplay. A versão localizada deve permitir ao jogador lidar com todos os elementos do gameplay (vistos acima) de uma maneira clara e objetiva. Assim como o público da versão original, o jogador da versão localizada deve sentir, como bem observam Mangiron e O’Hagan, que o game que têm em mãos não é uma mera “versão secundária”, inferior à original, mas que também foi projetado tendo ele (esse jogador) em mente, fazendo com que se sinta valorizado. O intuito é que o jogador se concentre apenas no gameplay, sem ter a sua atenção desviada por nada que possa vir a comprometer a sua experiência.

Como se viu anteriormente, os games são constituídos por objetivos, os quais, por sua vez, só serão alcançados após a superação de diversos desafios apresentados ao jogador. E tais desafios requerem que o jogador elabore a melhor estratégia - em suas escolhas, ações e decisões - para superá-los. É justamente aí que a tradução adquire uma importância vital para que esse processo transcorra de maneira normal. Uma tradução desatenta ou obscura poderá comprometer o fluxo natural desse processo, o que acabaria por interferir de maneira direta na gameplay experience. Pois, como atingir um objetivo se ele não é perfeitamente compreendido pelo jogador? Ou ainda, como o jogador irá desenvolver estratégias e tomar decisões se os desafios não estão claramente explicitados? Uma versão localizada nesses moldes faria com que o gameplay estivesse repleto de "pontos cegos", tornando o game demasiadamente complicado ou misterioso. Como resultado, o jogador estaria condicionado a um processo de tentativa e erro bem mais longo e frustrante do que o jogador da versão original, sendo obrigado a confiar em seus instintos para avançar no game. Por outro lado, uma tradução que leve em conta todos esses aspectos possibilitará ao jogador obter as informações necessárias para progredir no game, de modo a poder, assim, concentrar suas atenções apenas no gameplay, sem a necessidade de ter de "decifrar" o ambiente do game, garantindo, uma interação jogador/game bem sucedida, e, consequentemente, uma gameplay experience divertida. Em Cultural Localization: Orientation and Disorientation in Japanese Video ga-

\footnotetext{
${ }^{13}$ The main priority of game localisation is to preserve the gameplay experience for the target players, keeping the 'look and feel' of the original. The brief of the localiser is to produce a version that will allow the players to experience the game as if it were originally developed in their own language and to provide enjoyment equivalent to that felt by the players of the original version.
} 
mes (2007), Francesca Di Marco discorre sobre a essa perspectiva particular da localização de games ao afirmar que:

Em outras palavras, o objetivo da localização não é produzir uma equivalência literal do texto original, mas, ao contrário, é criar o mesmo efeito na 'game experience' para o jogador, tal qual o texto original buscou criar. ${ }^{14}$ (Di Marco, 2007, p. 7)

Vê-se, portanto, que a localização de games não se pauta por uma equivalência ao texto de partida, mas sim pela produção de um texto de chegada com base no conceito de gameplay experience, isto é, na experiência divertida que o game deverá proporcionar ao jogador. Isso não significa que não se parta de um texto original que serve como referência para o processo tradutório. Porém, os esforços do tradutor devem ser empreendidos no sentido de fazer tudo o que estiver ao seu alcance para reproduzir, facilitar e/ou aprimorar a gameplay experience da versão localizada.

Por exemplo, ao traduzir instruções para a realização de uma determinada missão, o foco do texto traduzido deve ser transmitir os meios necessários que permitam ao jogador concluir tal missão com sucesso, e não simplesmente ser estilisticamente correto e fiel ao original, podendo vir a comprometer a experiência. $\mathrm{O}$ mesmo se aplica no caso de termos/textos culturalmente marcados: deve-se buscar, na medida do possível, que o termo/texto traduzido possa criar certo grau de identificação com o jogador, ou seja, que lhe seja algo culturalmente reconhecível, procurando com isso produzir na gameplay experience a mesma sensação e o mesmo impacto que o termo/texto de partida provocou na versão original.

Diante de tudo o que foi visto até aqui, resta-nos examinar alguns exemplos a fim de observar na prática o funcionamento desse processo de localização e o impacto causado na gameplay experience. Serão analisados três exemplos retirados das versões em português brasileiro de três games: Mortal Kombat (Warner Bros./Nether Realm, 2011), Assassin's Creed Revelations (Ubisoft, 2011) e Max Payne (Remedy Entertainment /3D Realms/Gathering Of Developers, 2001).

\section{Exemplo 1: Mortal Kombat}

O primeiro exemplo analisado vem de Mortal Kombat (Warner Bros./Nether Realm, 2011), lançado no Brasil com o áudio original em inglês e textos em português brasileiro: trata-se do desafio 115 do modo “Torre dos Desafios”.

\footnotetext{
${ }^{14}$ In other words, the aim of localization is not to produce a literal equivalence of the original text, but rather to create the same effect in the game experience for the player as the original text sought to create.
} 


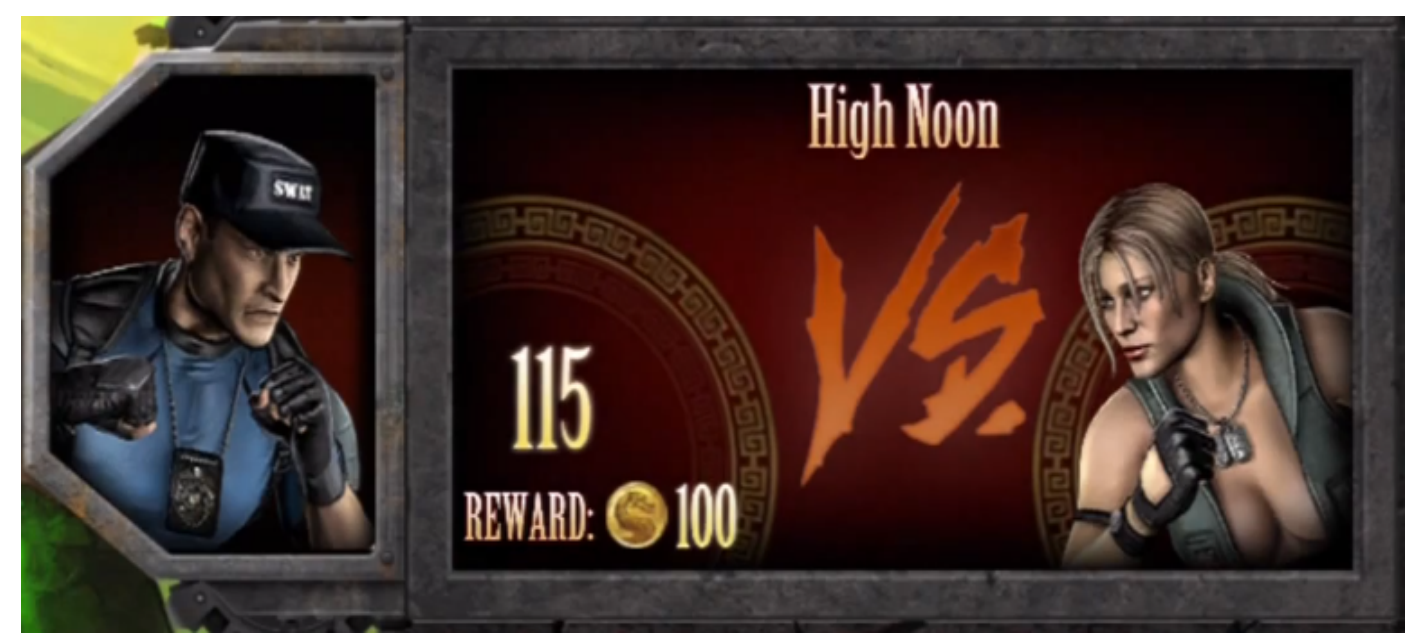

Imagem 1: High Noon - Desafio 115 na versão original em inglês

No desafio em questão, denominado na versão original de High Noon, o jogador controla o personagem Stryker, que é membro da SWAT (grupo de elite da polícia norte-americana) e, cujo objetivo é derrotar a personagem Sonya. Contudo, uma das regras do desafio estabelece que apenas Sonya pode se mover, não restando a Stryker outra alternativa a não ser atirar para conter o avanço e os ataques de Sonya.

O nome High Noon é proveniente do título de um filme do gênero faroeste de 1952, em que o delegado Will Kane (Gary Cooper), prestes a se casar com Amy (Gracy Kelly) e a deixar a cidade de Hadleyville, descobre que o criminoso Frank Miller (Ian Macdonald), capturado e lançado à prisão por ele, havia escapado e estava retornando à cidade no trem do meio-dia em busca de vingança. $\mathrm{O}$ filme recebeu no Brasil o título de Matar ou Morrer e era de se esperar que o nome do desafio seguisse o nome do filme. No entanto, não foi isso o que ocorreu. De fato, caso o desafio fosse intitulado de Matar ou Morrer, é muito provável que este não fosse imediatamente associado ao filme, visto que essa é uma expressão de uso corrente na língua portuguesa e utilizada em diversos contextos. Além disso, ao examinar os títulos de outros desafios na versão em português brasileiro, observamos que o desafio 175 foi nomeado de Matar ou Morrer (Going all out ${ }^{15}$ na versão original em inglês). Nele, o jogador controla o personagem Ermac, que deve derrotar Smoke em um duelo cujas regras impossibilitam qualquer movimento de defesa por parte dos lutadores, impedindo que consigam bloquear os golpes do adversário. Em outras palavras, todo e qualquer ataque efetuado por um dos lutadores causará sérios estragos em seu oponente. Isso não dá outra alternativa ao jogador a não ser permanecer na ofensiva, pois, caso não o faça, acabará sendo fatalmente derrotado. Dessa forma, observando o contexto de ambos os desafios, nota-se que o termo Matar ou Morrer acaba por se encaixar melhor no perfil do desafio 175, em virtude da impossibilidade de defesa e da necessidade contínua de atacar em busca da vitória. Já em High Noon, muito embora Stryker não possa se mover, a ele não foi vedada a possibilidade de bloquear os ataques de Sonya, ademais de poder usar seus movimentos de ataques de uma distância segura, mantendo a oponente afastada enquanto lhe inflige danos pesados com seus tiros e bombas. Assim, restava encontrar para a

\footnotetext{
${ }^{15}$ Algo como "Fazendo o (seu) melhor" ou "Dando o (seu) melhor".
} 
tradução de High Noon uma expressão que, de alguma maneira, resgatasse a essência e o contexto do original.

A despeito de o termo faroeste remeter ao contexto americano de filmes do referido gênero, buscou-se encontrar no contexto cultural brasileiro algo que pudesse refletir essa característica e que, ao mesmo tempo, fosse familiar ao público receptor. Nesse sentido, optou-se por nomear o desafio 115 de Faroeste Kaboclo ${ }^{16}$, em alusão à famosa canção da banda brasileira Legião Urbana. Apesar de a ambientação da música ser diferente daquela vista em High Noon (Brasília e Hadleyville, respectivamente), a história contada na canção possui elementos bastante semelhantes aos vistos no filme, como o contexto de violência e vingança encontrado ao longo da narrativa, a indecisão entre seguir o amor de uma mulher ou enfrentar o inimigo, tudo culminando em um duelo final entre o protagonista e o antagonista. Com isso, o termo Faroeste Kaboclo, por ser bastante conhecido em todo o Brasil, acabou permitindo que o efeito do original, isto é, todo o contexto de um típico faroeste fosse, de certa forma, apreendido e transmitido de uma maneira bem sucedida na versão em português brasileiro.

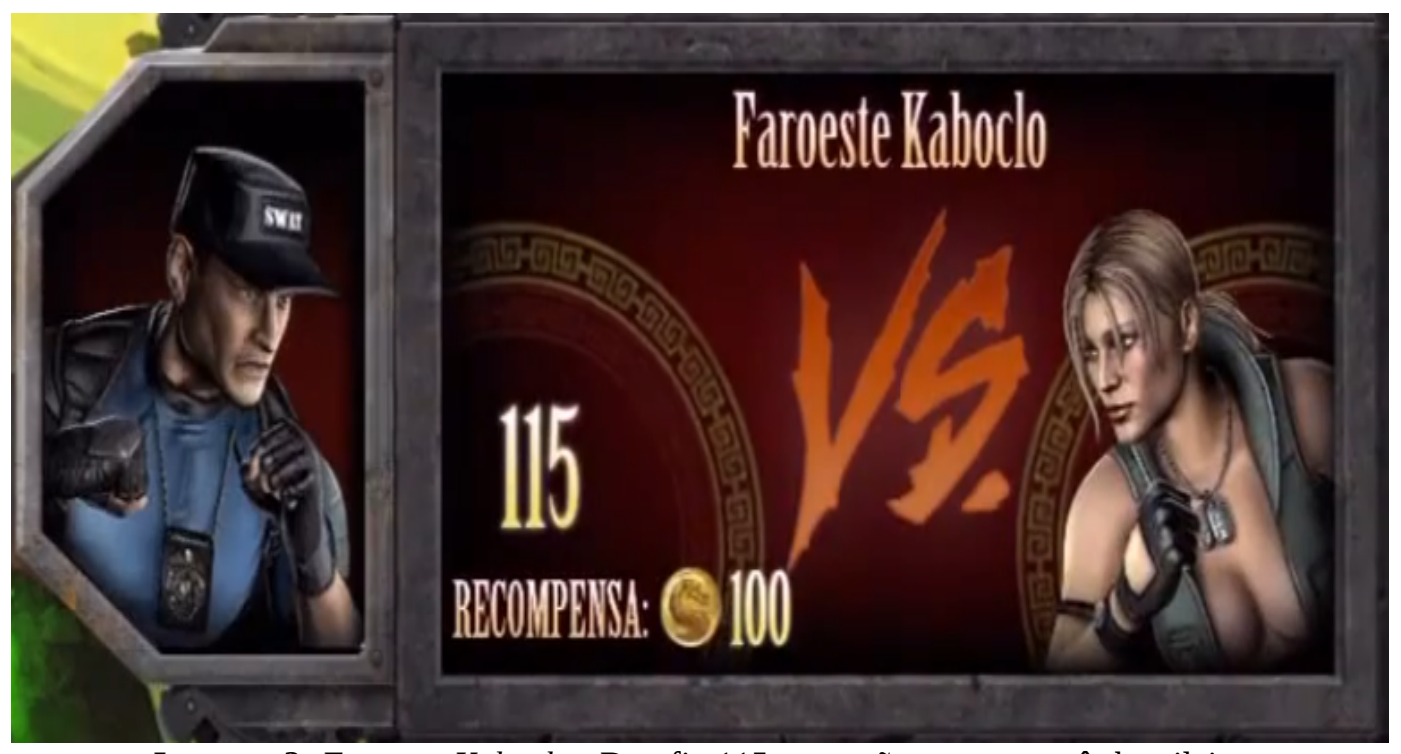

Imagem 2: Faroeste Kaboclo - Desafio 115 na versão em português brasileiro

\section{Exemplo 2: Assassin's Creed Revelations}

A exemplo de Mortal Kombat, Assassin's Creed Revelations (Ubisoft, 2011) também foi lançado no Brasil com textos em português brasileiro e áudio original em inglês. Antes de entrarmos diretamente no exemplo, faz-se necessária uma pequena explanação acerca da narrativa da série Assassin’s Creed. Ela gira em torno da luta milenar entre templários ${ }^{17}$ (cujo objetivo é dominar o mundo) e assas-

\footnotetext{
${ }^{16}$ O nome da canção, obviamente, é Faroeste Caboclo. Nesse caso, usou-se o “K” apenas para manter uma característica marcante da série Mortal Kombat, que é exatamente o de substituir, sempre que possível, o “C” por “K”, como é o caso de Kontent ou Krypt, que viraram Konteúdo e Kripta na versão em português brasileiro.

${ }^{17}$ A ordem dos templários, de caráter militar e religiosa, foi fundada por Hugues de Payn em 1118, em Jerusalém, e extinta pelo papa são Clemente em 1317. Porém, na série Assassin's Creed, essa in-
} 
sinos (que tentam proteger o mundo da dominação e controle templários). Nesse contexto, há um personagem em nosso tempo presente (chamado Desmond nos cinco primeiros games da série ${ }^{18}$ ), que acessa uma máquina chamada Animus, que lhe permite, por meio do acesso à sua "memória genética”, reviver aquelas de seus ancestrais (que basicamente são os personagens principais da série): Altair (Assassin's Creed, cuja história se passa no período das Cruzadas), Ezio (Assassin's Creed II, Assassin's Creed Brotherhood, cujas narrativas se situam na Itália Renascentista, e Assassin's Creed Revelations, situada na Constantinopla Otomana) e Connor (Assassin's Creed III, cuja história se desenvolve durante o processo de independência dos EUA). Após essa breve introdução contextual, passemos ao exemplo propriamente dito.

O exemplo a seguir ocorre durante uma sessão na Animus em que Desmond acessa as memórias de Ezio durante sua viagem a Turquia Otomana, mais precisamente durante a Sequência 3: Achados e Perdidos, Memória 1: O Prisioneiro. Nela, o protagonista Ezio deve libertar um prisioneiro que havia sido capturado após roubar alimentos e, para isso, precisa encontrar o guarda que possui a chave da prisão e recuperá-la. A grande questão aqui ocorre na mensagem que instrui o jogador sobre como obter a Sincronização Total $^{19}$ da missão. O texto em inglês mostra a seguinte mensagem:

formação é reorganizada, de modo a se adequar ao contexto narrativo da série. Em Assassin's Creed II (Ubisoft, 2010), o protagonista Ezio é informado por seu tio Mario que os templários não haviam sido extintos como se pensava: “A História nos ensina que eles foram dissolvidos há quase 200 anos na França. Só que não foram. Simplesmente passaram para a clandestinidade, de onde continuaram o seu trabalho obras nefasto [History teaches us they were disbanded nearly 200 years ago in France. Only they weren't. Merely pushed underground where they continued their nefarious work.]” (Ubisoft, 2010, Sequência 3: Requiescat in Pace, Memória 3: Practice Makes Perfect - tradução nossa). Esta nova perspectiva permite situar a luta entre assassinos e templários não apenas no passado, mas também no presente, fazendo com que a disputa entre ambas as ordens se estenda desde as Cruzadas até o tempo presente. Além disso, devido ao fato de que contextos históricos do passado sejam "revividos” por um personagem situado no presente faz com que as lutas de assassinos e templários em tempos antigos acabem por ter implicações também no presente.

${ }^{18}$ Assassin's Creed (Ubisoft, 2007), Assassin's Creed II (Ubisoft, 2009), Assassin's Creed Brotherhood (Ubisoft, 2010), Assassin's Creed Revelations (Ubisoft, 2011) e Assassin's Creed III (Ubisoft, 2012).

${ }^{19}$ As missões em Assassin's Creed Revelations estão estruturadas da seguinte maneira: elas estão organizadas em Sequências (que basicamente funcionam como capítulos), as quais, por sua vez, são divididas em Memórias. Cada memória possui um objetivo principal e um objetivo secundário, e somente a consecução de ambos permitirá que o jogador obtenha a Sincronização Total, isto é, $100 \%$ de sincronização. No caso do objetivo secundário, pelo fato de Desmond "reviver” as memórias da vida de seu ancestral Ezio, o jogador deverá atingi-lo exatamente da mesma maneira que seu ancestral o fez. No exemplo em questão, o objetivo principal é libertar o prisioneiro e o objetivo secundário é obter a chave. O jogador poderá recuperar a chave de várias formas (como se vê mais abaixo), mas só obterá a sincronização total se libertar o prisioneiro após roubar a chave do guarda sem que esse perceba. 


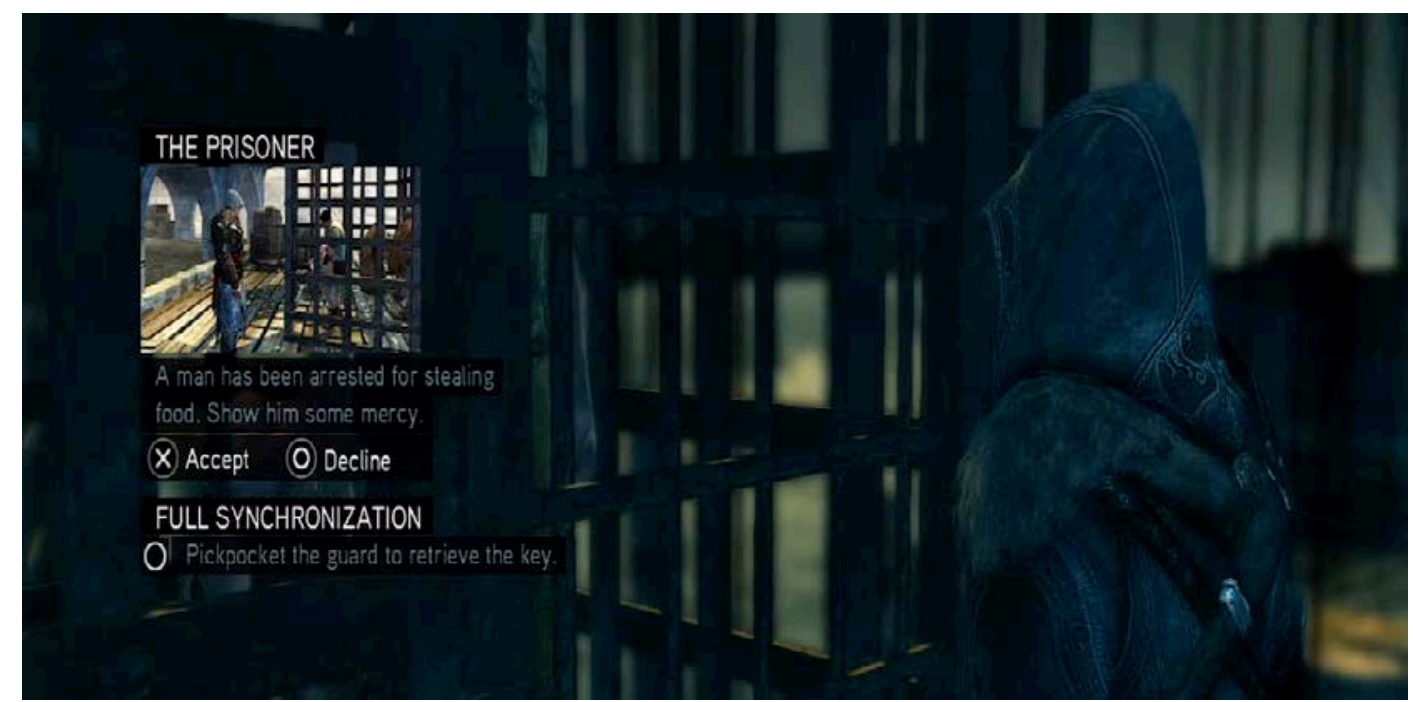

Imagem 3: Tela de abertura da missão The Prisoner na versão original em inglês

Por outro lado, o texto em português brasileiro exibe a mesma mensagem da seguinte maneira:

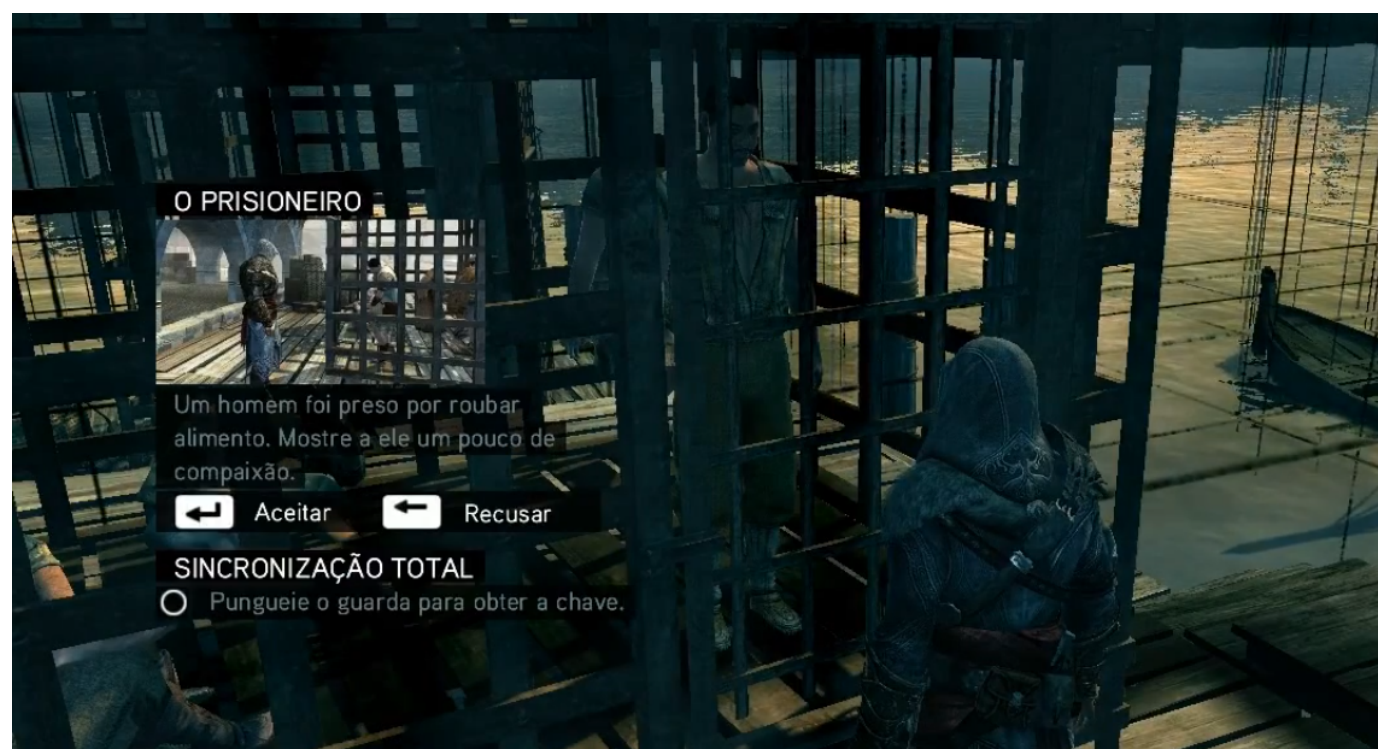

Imagem 4: Tela de abertura da missão O Prisioneiro na versão original em português brasileiro

Ocorre que a frase "Pickpocket the guard to retrieve the key" traz uma mensagem clara e inteligível, sendo facilmente reconhecida por qualquer falante de inglês, fornecendo as informações necessárias para que a sincronização total seja atingida de forma precisa. Por outro lado, lemos em português brasileiro "Pungueie o guarda para obter a chave", uma mensagem um tanto obscura, em função do uso do verbo punguear. Ao contrário de pickpocket, que é um termo de uso corrente no inglês moderno, punguear é um termo pouquíssimo utilizado por falantes do português brasileiro, fazendo com que a frase acima acabe soando bastante estranha e de difícil compreensão. Pelo fato de que existem várias maneiras de Ezio obter a chave (nocautear o guarda, matá-lo, roubá-lo sem ser detectado), os jogadores da versão em inglês sabem exatamente o que fazer para atingir a sincronização total, ao passo que os jogadores da versão em português brasileiro muito provavelmente terão dificuldades para alcançar tal sincronização, já que punguear não é um termo que lhes 
soa familiar. Isso acaba por provocar uma interferência na gameplay experience, na medida em que o efeito de clareza do original transmitido por pickpocket é substituído pelo efeito de "mistério" causado por punguear. Uma possível razão para o uso de punguear em detrimento, por exemplo, de bater carteira (umas traduções possíveis para pickpocket) seria uma tentativa de adequação ao período histórico do game, visto que a história de Assassin's Creed Revelations se passa em 1512. Sob esse prisma, vemos que, realmente, o uso de bater carteira seria inviável, uma vez que, segundo o dicionário Houaiss, a primeira datação da palavra carteira na língua portuguesa provém de 1727 (Dicionário Houaiss, 2001-2009). Contudo, o uso de punguear tão-pouco se mostra factível, visto que, também de acordo com o dicionário Hoauiss, a primeira datação de uma palavra relacionada ao contexto de punguear (punguista) é de 1899 (Dicionário Houaiss, 2001-2009), ou seja, é até mais recente do que o da própria palavra carteira. Diante desse cenário, duas possibilidades poderiam ser implementadas a fim de tentar resgatar a essência do original:

\section{a) Ignorar o contexto histórico e utilizar a expressão bater carteira:}

Ao contrário do que poderia parecer, o uso de bater carteira em um período histórico em que não existiam carteiras não se tornaria inverossímil. Pelo contrário, esse uso seria referendado pela própria história da série: no primeiro Assassin's Creed, há uma cena em que, após reviver uma das memórias de seu ancestral Altair, Desmond faz uma observação a Lucy (uma das operadoras da Animus) sobre o modo de falar das pessoas na Terra Santa. Ao que Lucy lhe responde: "Você provavelmente notou que o inglês se tornou a língua oficial da Terra Santa [...] A Animus está traduzindo as falas que considera vitais para um inglês mais moderno. Então, espere alguns anacronismos” ${ }^{20}$ (Ubisoft, 2007, Bloco de Memória 2). Dessa forma, bater carteira entraria nessa categoria de “anacronismos” e seu uso poderia ser atribuído ao software da Animus, que traduz termos considerados importantes para uma linguagem mais moderna.

\section{b) Levar em conta o contexto histórico e usar o termo roubar:}

Pelo que se viu até aqui, os termos bater carteira e punguear não se encaixariam no período histórico em questão. No entanto, poder-se-ia ter um termo que solucionasse a questão da adequação ao período histórico: o termo roubar. A despeito de ser um termo bem mais abrangente em comparação com bater carteira e punguear, roubar é o termo mais usado em português brasileiro para referir-se à qualquer tipo de apropriação de algo que pertence a outra pessoa sem seu consentimento, sendo utilizado pela maioria esmagadora dos falantes de português independentemente de classe social ou nível de escolaridade. É bastante comum ouvirmos na imprensa (que tende a primar por uma linguagem mais culta), frases do tipo " $\mathrm{Fu}$ lano teve a sua carteira roubada", ao passo que seus equivalentes "Fulano teve a sua carteira batida", ou ainda "Fulano teve a sua carteira pungueada", são praticamente inexistentes, devido ao estranhamento que provocariam. Além de ser uma palavra de uso corrente, aproximando-se, assim, de pickpocket, roubar também se adequaria ao contexto histórico: segundo o dicionário Houaiss, o primeiro registro

\footnotetext{
${ }^{20}$ You've probably noticed that English has become the official language of the Holy Land [...] The Animus is translating speech it deems vital into more modern English. So expect a few anachronisms.
} 
da palavra roubar na língua portuguesa advém do século XIII, isto é, dos anos 1200. Dessa forma, ademais de apreender o mesmo efeito causado por pickpocket, roubar também seria apropriado para o contexto histórico do game, na medida em que sua primeira aparição em português se deu aproximadamente três séculos antes do período histórico retratado. Diante disso, "Roube o guarda para obter a chave" permitiria que a sincronização total fosse feita de maneira bem mais tranquila, resgatando, com isso, o mesmo impacto que a frase "Pickpocket the guard to retrieve the key" tem na versão em inglês.

\section{Exemplo 3: Max Payne}

A versão em português brasileiro de Max Payne (Remedy Entertainment /3D Realms/Gathering Of Developers, 2001) teve tanto o áudio quanto os textos traduzidos para o português, embora somente a versão para PC tenha sido localizada. Max Payne apresenta talvez o maior exemplo do quanto a (não)tradução de determinado trecho pode afetar seriamente a gameplay experience. Quando se decide pela localização de determinado game, pensa-se normalmente na tradução dos textos (legendas e interface do usuário), e, em muitos casos, também do áudio. As artes gráficas presentes nos cenários dos games, isto é, placas, cartazes, sinalizações, etc, costumam ser deixadas de lado, e geralmente não fazem parte do material a ser traduzido, pois o impacto que essa não-tradução poderia causar na gameplay experience tende a ser praticamente nulo. Porém, não foi o que ocorreu em Max Payne.

No caso de Max Payne, a narrativa está intimamente atrelada à cidade de Nova Iorque: a cidade não apenas é mencionada ao longo de todo o game, mas também o incessante cair da neve acentuando o clima de inverno rigoroso acaba por aumentar a sensação de imersão ao ambiente da cidade. Por essa razão, nada mais natural do que esperar que as artes gráficas também fossem mantidas em inglês. $\mathrm{Na}$ maior parte do game, essa decisão não afetou o gameplay, permitindo ao jogador pensar em estratégias, tomar suas decisões, superar seus desafios e conquistar objetivos normalmente. Em um trecho, entretanto, a não tradução acabou por causar uma interferência clara no gameplay que veio a comprometer a gameplay experience de maneira decisiva. Na Parte II: Um Dia Frio no Inferno, Capítulo II: Uma Oferta Irrecusável, o protagonista (Max Payne) investiga o navio de carga Charon. Durante suas investigações, Max acaba se deparando com inimigos que tentam de todas as formas impedir seu sucesso. Em um trecho dessa missão, uma ponte móvel, que poderia servir como caminho para Max Payne, foi levantada por inimigos, com vistas a conter seu avanço. Ao buscar um caminho alternativo, ele se depara com uma cerca e com um caminhão estacionado do lado oposto, também bloqueando uma possível passagem para que prosseguisse. 

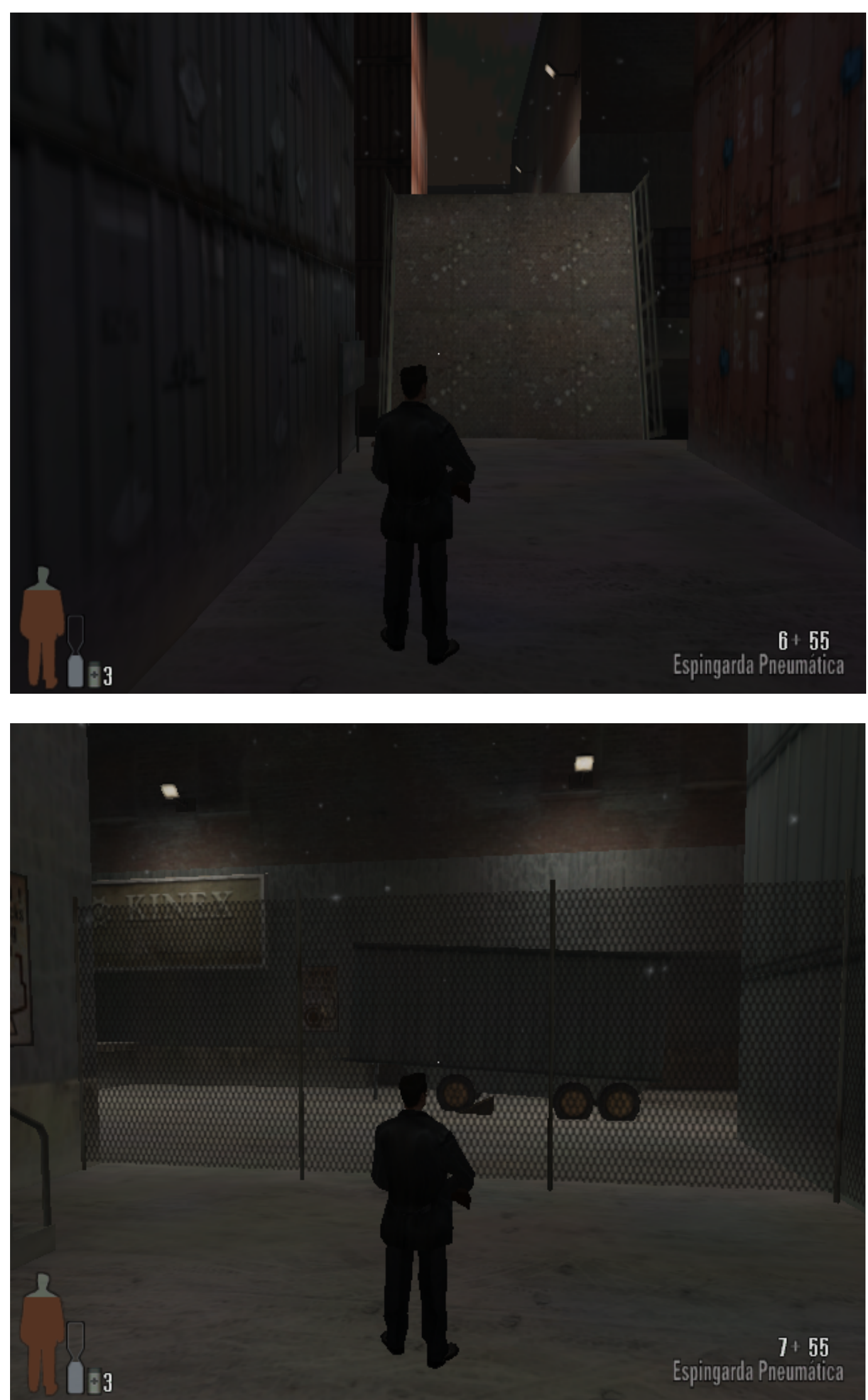

Imagens 5 e 6: Max Payne bloqueado tanto pela ponte (esq.) quanto pela cerca (dir.). 
Vendo-se bloqueado por ambos os lados, o jogador passa então a testar todas as possibilidades de encontrar uma passagem que lhe permita prosseguir no game. Após seguidas tentativas de busca por uma solução tanto do lado da ponte como junto à cerca (como tentar baixar a ponte, tentar pular no fosso entre as duas partes da ponte, atirar na cerca, etc.), todas sem sucesso, o jogador passa a se sentir frustrado por não saber mais o que fazer para avançar no game. Os jogadores mais atentos muito provavelmente percebem a presença do seguinte cartaz ao lado da cerca:

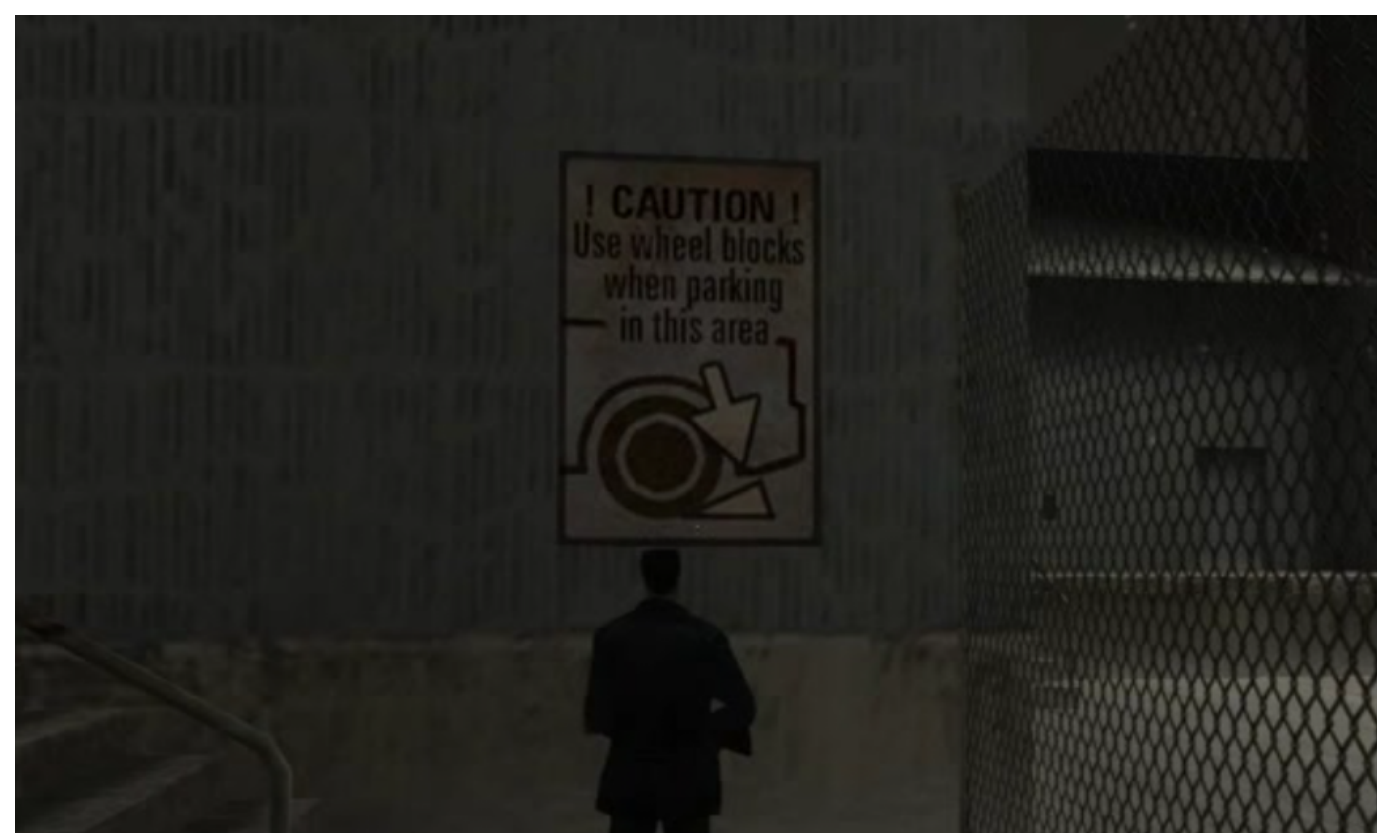

Imagem 7: Cartaz junto à cerca contendo as instruções para prosseguir no game

Ao observarmos esse cartaz, vemos que ele contém uma informação-chave para o jogador prosseguir no game. Junto à mensagem "Caution! Use wheel blocks when parking in this area" (algo como Cuidado! Use calços nas rodas ao estacionar nesta área) há um desenho com um calço segurando uma roda e impedindo um veículo de se mover. De posse dessa informação e analisando novamente o ambiente ao redor da cerca, vemos que a solução para esse desafio resume-se a atirar no calço que segura o caminhão estacionado do lado oposto da cerca, para que esse se mova, avance sobre a ponte e a desbloqueie, abrindo caminho para o avanço de Max. E é aí que reside a grande questão. $\mathrm{O}$ fato de a mensagem estar em inglês na versão em português brasileiro, aliado à questão de que todas as demais artes gráficas também foram mantidas em inglês, faz com que instintivamente o jogador simplesmente a ignore, haja vista que o seu foco principal está em superar o desafio. E mesmo que o jogador venha a ler o conteúdo da mensagem no cartaz, a sua compreensão estará inevitavelmente restrita àqueles que têm um bom domínio do inglês, relegando os que não o têm à sua própria sorte, mesmo se tratando da versão em português brasileiro do game. A interferência na gameplay experience é evidente, pois a não compreensão do conteúdo dessa mensagem acabou por impedir que muitos jogadores pudessem prosseguir no game, fazendo com que tenham ficado presos nesse estágio da narrativa, restando, ao invés da diversão, os sentimentos de frustração e, por que não, irritação. A decisão de deixar as artes gráficas no original em inglês foi acertada no sentido de tentar reproduzir a ambientação da cidade de 
Nova Iorque. Porém, nesse caso específico, por envolver diretamente o gameplay, a simples tradução desse cartaz teria evitado a enorme dor de cabeça e a decepção que muitos jogadores efetivamente tiveram ao se sentirem incapazes de avançar na narrativa.

\section{Conclusão}

Como se viu ao longo desse texto, a tradução está intrinsecamente ligada ao sucesso ou não da versão localizada. Durante o processo de localização, o objetivo primordial deve estar sempre em transmitir um nível de gameplay experience semelhante àquele vivenciado pelo jogador da versão original. Afinal, quando se lida com videogames, há que se ter sempre em mente que, como ressalta O’Hagan, a localização de games não envolve uma simples tradução de um idioma, mas sim, a tradução de toda uma experiência (O’Hagan, 2007, p.1). E é justamente essa experiência que permitirá que o game possa atingir a sua principal meta, que é a de divertir e oferecer ao jogador uma experiência agradável, prazerosa e que poderá marcar para sempre o curso de sua vida.

Ricardo Vinicius Ferraz de Souza ricardovinicius_souza@hotmail.com Mestrando em Estudos da Tradução, Universidade de São Paulo 


\section{Referência bibliográficas}

AdAms, E. Fundamentals of Game Design ( $2^{a}$ Edição). Berkeley: New Riders, 2009.

Di MARCO, F. "Cultural Localization: Orientation and Disorientation in Japanese Video games”. IN: Tradumàtica, núm. 5, 2007, p.1-8. Disponível em: http://www.fti.uab.cat/tradumatica/revista/num5/articles/06/06.pdf < Acesso em: 12 jan. 2014>

DicionÁRio HouAISS (versão 3.0 em CD-ROM). Instituto Antônio Houaiss, (C) 2001-2009. Editora Objetiva, junho de 2009

FERnAndeZ, A. "Fun Experience with Digital Games: A Model Proposition”. Workshop - Design Principles for Software that engages its users. Interact 2007, Rio de Janeiro, 2007, p.1-11. Disponível em: http://fun-ofuse.org/interact2007/papers/FunExperienceWithDigitalGames.pdf <Acesso em: 9 jan. 2014>

LipPe, P. H. L. “Análise: The Legend of Zelda: A Link Between Worlds”. IN: UOL Jogos, 23 de novembro de 2013. Disponível em: http://jogos.uol.com.br/3ds/analises/the-legend-of-zelda-a-link-to-the-past2.htm <Acesso em: 5 jan. 2014>

MANGIRON, C. \& O’HAGAN, M. “Game Localisation: Unleashing Imagination with 'Restricted' Translation”. IN: The Journal of Specialised Translation, issue 6, 2006, p.10-21. Disponível em : http://www.jostrans.org/issue06/art_ohagan.pdf <Acesso em: 10 jan. 2014>

Nacke, L.E., Drachen, A., Goebel, S. "Methods for Evaluating Gameplay Experience in a Serious Gaming Context”. IN: International Journal of Computer Science in Sport, vol. 9 no. 2, 2010, p.1-12, Darmstadt, Alemanha. Disponível em: http://hci.usask.ca/uploads/174-Methods-for-EvaluatingGameplay-Experience-in-a-Serious-Gaming-Context.pdf <Acesso em: 8 jan. 2014>

NovaK, J. Game Development Essentials (3rd Edition). Clifton Park: Delmar Cengage Learning, 2012.

O'HAGAN, Minako. Video games as a new domain for translation research: from translating text to translating experience. IN: Tradumàtica, n. 5, 2007, p. 17. Disponível em: http://ddd.uab.cat/pub/tradumatica/15787559n5a9.pdf <Acesso em: 11 jan. 2014>

Rollings, A \& Morris, D. Game Architecture and Design: A New Edition. Indianápolis: New Riders, 2004.

StAPleton, D. “XCOM: Enemy Within Review”. IN: IGN, 11 de novembro de 2013. Disponível em: http://www.ign.com/articles/2013/11/11/xcomenemy-within-review < Acesso em: 5 jan. 2014>

\section{Games Citados}

ASSSASSIN'S CREED. EUA, 2007. Ubisoft: Playstation 3, Xbox 360, PC (Windows) ASSSASSIN'S CREED II. EUA, 2009. Ubisoft: Playstation 3, Xbox 360, PC (Windows) ASSSASSIN'S CREED BROTHERHOOD. EUA, 2010; Brasil, 2010. Ubisoft: Playstation 3, Xbox 360, PC (Windows) 
ASSSASSIN's CREED REVELATIONS. EUA, 2011; Brasil, 2011. Ubisoft: Playstation 3, Xbox 360, PC (Windows)

ASSSASSIN's CREED III. EUA, 2012; Brasil, 2012. Ubisoft: Playstation 3, Xbox 360, PC (Windows)

MAX PAYNE. EUA, 2001; Brasil 2001. Remedy Entertainment /3D Realms/Gathering of Developers: PC (Windows).

Mortal Kombat. EUA, 2011; Brasil, 2011. Warner Bros. Interactive Entertainment/NetherRealm Studios: Playstation 3/ Xbox 360

THE LEGEND OF ZELDA: A LINK BETWEEN WORLDS. EUA, 2013; Japão, 2013. Nintendo: Nintendo 3DS

Xсом: ENEMY Within. EUA, 2013. 2K Games/ Firaxis: Playstation 3, Xbox 360, PC (Windows e OS X) 